\title{
Influence of Polar Residue Deletions on Lipid-Protein Interactions with the Myelin Proteolipid Protein. Spin-Label ESR Studies with DM-20/Lipid Recombinants
}

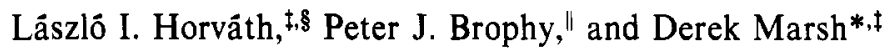 \\ Abteilung Spektroskopie, Max-Planck-Institut für biophysikalische Chemie, D-3400 Göttingen, FRG, and Department of \\ Biological Sciences, Stirling University, Stirling, U.K. \\ Received December 8, 1989; Revised Manuscript Received January 19, 1990
}

\begin{abstract}
The lipid specificities of two related integral membrane proteins of central nervous system myelin, the proteolipid (PLP) and DM-20 proteins, which differ only by the deletion of a polar stretch of 35 contiguous amino acid residues, were studied with spin-labeled lipids after reconstitution into dimyristoylphosphatidylcholine. The selectivity in populating lipid association sites at the protein interface and in modulating the lipid exchange between protein and bulk lipid sites was quantitated by the relative association constants and the off-rate constants for exchange, respectively, for both proteins. The sequence deleted in DM-20 (residues 116-150 of PLP) is found to play a major role in determining the lipid selectivity for the parent PLP protein.
\end{abstract}

$T_{\text {he }}$ ESR $^{1}$ spectra of spin-labeled lipid molecules have previously been used to determine the pattern of specificity of the lipid interaction with a range of different integral membrane proteins [see, e.g., Marsh (1985) and Devaux and Seigneuret (1985)]. Selectivity in the lipid-protein interaction is found for various negatively charged lipids, and the selectivity pattern differs for different proteins, corresponding to their individual amino acid sequences. In certain cases, the pattern of lipid specificity correlates very well with the functional effects of different lipids on the protein [see Marsh (1987) for a review].

Experiments on the origin of the lipid selectivity have demonstrated a decreasing selectivity with increasing ionic strength, indicating the importance of electrostatic interactions (Esmann \& Marsh, 1985; Brotherus et al., 1980; Horväth et al., 1988b). Reversing the charge on the lysine groups of cytochrome oxidase by covalent modification has shown that these residues are involved in determining the lipid selectivity (Powell et al., 1987). Covalent attachment of chemically reactive negatively charged phospholipid analogues has allowed identification of the subunits of cytochrome oxidase which bear the lysine residues contributing to the selectivity (McMillen et al., 1986).

A direct approach to the problem of identifying the protein residues involved would be to investigate the effects of sitedirected mutagenesis of the protein on the lipid selectivity pattern. The proteolipid protein (PLP) from central nervous system myelin offers a unique opportunity in this respect, since a naturally occurring mutant is available in myelin. The native apoprotein is 276 residues in length, and the DM-20 mutart is a closely related protein of 241 residues, which is derived from the parent PLP simply by deletion of 35 amino acids corresponding to residue positions $116-150$ in the native protein (Nave et al., 1987; Simons et al., 1987). The deleted sequence is highly polar in nature, containing three arginine, two lysine residues, and one each of glutamic and aspartic acids in bovine

\footnotetext{
'Max-Planck-Institut für biophysikalische Chemie.

Permanent address: Biological Research Center, Hungarian Academy of Sciences, Szeged, Hungary.

"University of Stirling.
}

DM-20. According to the model of Stoffel et al. (1984), this sequence is contained in the largest of the extracytosolic loops of the integral protein structure. ESR studies of spin-labeled lipids in reconstituted DM-20 systems therefore allow determination of the effects of this highly basic portion of the PLP molecule on the lipid selectivity pattern, essentially without disturbing the hydrophobic region, and hence the number of intramembranous lipid sites, in the protein. It is demonstrated here that the positively charged stretch of residues from position 116 to position 150 plays an important role in determining the selectivity of interaction with the myelin proteolipid protein.

\section{Materials and Methods}

Materials. Dimyristoylphosphatidylcholine (DMPC) was from Fluka (Buchs, Switzerland). Hepes was from Sigma (St. Louis, MO). 14-SASL was prepared according to the method of Hubbell and McConnell (1971) and acylated at the $s n-2$ position of lysophosphatidylcholine yielding 14-PCSL (Boss et al., 1975). The spin-labeled phospholipids 14-PGSL, 14PSSL, and 14-PASL were prepared from 14-PCSL by transphosphatidylation catalyzed by phospholipase D [for details, see Marsh and Watts (1982)].

Protein Purification and Reconstitution. Myelin was extracted from bovine spinal cord and delipidated by gel filtration on Sephadex LH-20 (Pharmacia, Sweden) as described by Gagnon et al. (1971). SDS-polyacrylamide gel electrophoresis (Laemmli, 1970) of the delipidated protein revealed two bands corresponding to the myelin proteolipid protein (PLP) and the related protein of $23 \mathrm{kDa}$ (DM-20), in a ratio of approximately 2.5:1. No low molecular mass proteins $(12 \mathrm{kDa})$ could be found. DM-20 was further purified to near homogeneity

\footnotetext{
${ }^{1}$ Abbreviations; 14-PCSL, -PGSL, -PSSL, and -PASL, 1-acyl-2[13-(4,4-dimethyl-3-oxy-2-butyl-2-oxazolidinyl)tridecanoyl]-sn-glycero3-phosphocholine, -phosphoglycerol, -phosphoserine, and -phosphoric acid; 14-SASL, 13-(4,4-dimethyl-3-oxy-2-butyl-2-oxazolidinyl)tridecanoic acid; EDTA, ethylenediaminetetraacetic acid; DMPC, 1,2-dimyristoyl-sn-glycero-3-phosphocholine; Hepes, $N$-(2-hydroxyethyl)piperazine- $N^{\prime}-2$-ethanesulfonic acid; DM-20, the $23-\mathrm{kDa}$ myelin protein; PLP, myelin proteolipid apoprotein; ESR, electron spin resonance.
} 
according to the method of Trifilieff et al. (1985). The monomer molecular masses of PLP and DM-20 were taken as 25 and $23 \mathrm{kDa}$, respectively.

The DM-20 protein or the natural mixture of the proteolipid apoprotein and DM-20 (PLP + DM-20) was reconstituted with DMPC by dissolving both constituents in freshly distilled 2-chloroethanol and dialyzing against three changes of reconstitution buffer (100 mM NaCl, $1 \mathrm{mM}$ EDTA, $2 \mathrm{mM}$ Hepes, pH 7.4) as previously described (Boggs et al., 1976; Brophy, 1977). The homogeneity of protein incorporation was verified by sucrose gradient centrifugation for $3 \mathrm{~h}$ at 40000 $\mathrm{rpm}(10-55 \%$ sucrose in reconstitution buffer; Beckman SW $40 \mathrm{Ti}$ rotor), and the position of the single band was consistent with the lipid-to-protein ratio of the samples. Lipid and protein contents were determined by the methods of Eibl and Lands (1969) and Lowry et al. (1951), respectively.

ESR Spectroscopy. Single batches of dialyzed DM-20/ DMPC or (PLP + DM-20)/DMPC complexes were divided into several aliquots in order to ensure an identical lipid/protein ratio. Samples were spin-labeled from ethanolic solution at a level of $10 \mu \mathrm{g} / \mathrm{mg}$ DMPC, and incubated at $4{ }^{\circ} \mathrm{C}$ for $45 \mathrm{~min}$. Then each aliquot was pelleted, resuspended in salt-free buffer (1 mM EDTA, $2 \mathrm{mM}$ Hepes, $\mathrm{pH} 8.5$ ), and transferred to sealed $100-\mu \mathrm{L}$ capillary tubes. ESR spectra were recorded on a Varian E-12 Century Line spectrometer with nitrogen gas flow temperature regulation. Spectra were digitized with either a Digital Equipment Co. PDP11/LPS or a Tecmar Lab Master/IBM PC system and software written by Drs. W. Möller and M. D. King. Spectral subtractions were performed with interactive graphics, using software written by $\mathrm{Dr}$. W. Möller of this Institute; details of spectral subtractions are given in Marsh (1982). Spectral simulations of two-component spectra were performed with the exchange-coupled Bloch equations (Horvāth et al., 1988a; Marsh \& Horvāth, 1989).

\section{RESULTS}

Lipid Specificity. The lipid selectivities of the myelin DM20 and PLP proteins were studied by comparing the different spin-labels in complexes of fixed lipid/protein ratio. The ESR spectra of C-14 spin-labeled stearic acid and various C-14 spin-labeled phospholipids in DM-20/DMPC complexes and in complexes of the protein mixture (PLP + DM-20)/DMPC of mean lipid/protein ratio of $28: 1 \mathrm{~mol} / \mathrm{mol}$ are shown in Figure 1. All spectra consist of two components, but with different proportions of the two components corresponding to the fluid and motionally restricted spin-labeled lipids. Differences between the two proteins reflect the differing degrees of selectivity of the various lipids at the lipid-protein interface of DM-20 and PLP. These differences are particularly pronounced in the case of the acidic lipids 14-SASL and 14 . PASL, which show the highest selectivity for both proteins. The fractions $f$ of the motionally restricted components were determined by spectral subtractions using libraries of spectra from DMPC and PLP alone and are given in Table I.

It was shown previously (Brophy et al., 1984) that the number of association sites $N_{1}$ on PLP is the same for these lipids. Because the intramembranous sections of the DM-20 protein are identical with those of PLP, it may also be reasonably assumed that the value of $N_{1}$ is the same as that for PLP and is identical for the different lipids. Therefore, the relative association constants $K_{\mathrm{r}}$ can be calculated directly from the ratios of the double-integrated intensities of the fluid and motionally restricted components, $n_{\mathrm{f}}{ }^{*} / n_{\mathrm{b}}{ }^{*}$, relative to that for spin-labeled PC [see, e.g., Marsh (1985)]:

$$
\left(n_{\mathrm{f}}^{*} / n_{\mathrm{b}}{ }^{*}\right)^{\mathrm{PC}} /\left(n_{\mathrm{f}}^{*} / n_{\mathrm{b}}{ }^{*}\right)^{\mathrm{L}}=K_{\mathrm{r}}^{\mathrm{L}} / K_{\mathrm{r}}^{\mathrm{PC}}
$$

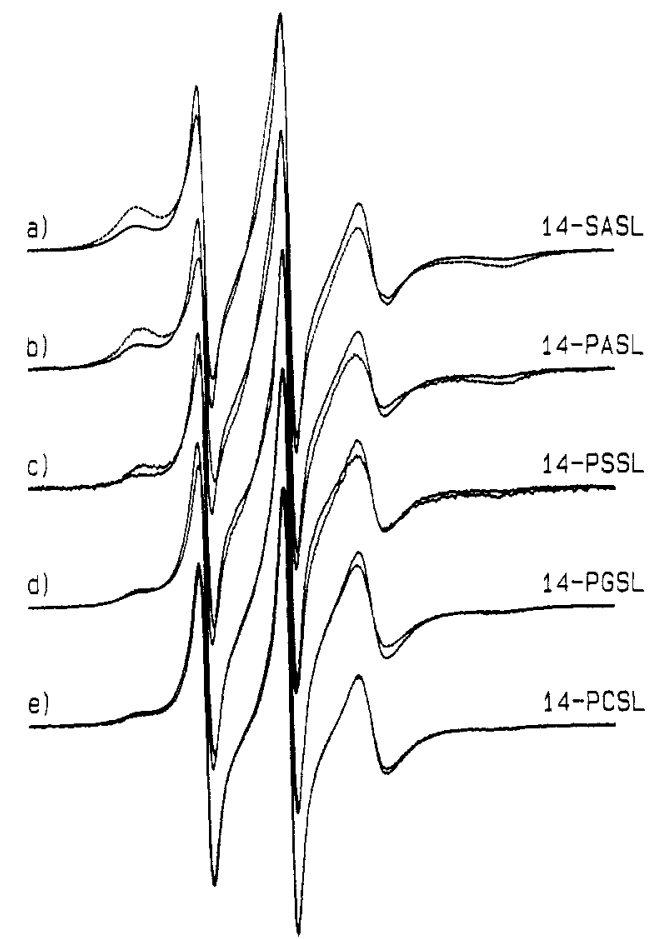

FIGURE 1: ESR spectra of different spin-labeled lipids in DM-20/ DMPC (full lines) and (DM-20 + PLP)/DMPC (dashed lines) recombinants of lipid/protein ratio $28: 1 \mathrm{~mol} / \mathrm{mol}$, at $T=30^{\circ} \mathrm{C}$ : (a) stearic acid spin-label, 14-SASL; (b) phosphatidic acid spin-label, 14-PASL; (c) phosphatidylserine spin-label, 14-PSSL; (d) phosphatidylglycerol spin-label, 14-PGSL; (e) phosphatidylcholine spin-label, 14-PCSL. Total scan width $=10 \mathrm{mT}$.

Table I: Selectivity of Spin-Labeled Lipids in Myelin DM-20/Dimyristoylphosphatidylcholine and in the Mixed (PLP + DM-20)/Dimyristoylphosphatidylcholine Recombinants of Lipid/Protein Ratio $28: 1 \mathrm{~mol} / \mathrm{mol}^{\circ}$

\begin{tabular}{|c|c|c|c|c|c|c|}
\hline \multirow[b]{2}{*}{ label } & \multicolumn{3}{|c|}{ DM-20 } & \multicolumn{3}{|c|}{ PLP + DM-20 } \\
\hline & $f$ & $K_{\mathrm{r}}^{\mathrm{L}} / K_{\mathrm{f}}^{\mathrm{PC}}$ & $\begin{array}{c}\Delta G \\
(\mathrm{~kJ} / \mathrm{mol})\end{array}$ & $f$ & $K_{\mathrm{r}}^{\mathrm{L}} / K_{\mathrm{r}}{ }^{\mathrm{PC}}$ & $\begin{array}{c}\Delta G \\
(\mathrm{~kJ} / \mathrm{mol})\end{array}$ \\
\hline 14-PASL & 0.64 & 2.46 & -2.2 & 0.81 & 5.88 & -4.3 \\
\hline 14-SASL & 0.61 & 2.16 & -1.9 & 0.76 & 4.37 & -3.6 \\
\hline 14-PSSL & 0.47 & 1.22 & -0.5 & 0.57 & 1.83 & -1.5 \\
\hline 14-PGSL & 0.43 & 1.04 & -0.1 & 0.52 & 1.50 & -1.0 \\
\hline 14-PCSL & 0.44 & 1.09 & -0.2 & 0.42 & 1.00 & 0.0 \\
\hline
\end{tabular}

${ }^{a} T=30^{\circ} \mathrm{C}$. Notation: $f$, fraction of motionally restricted spin-label; $K_{\mathrm{r}}^{\mathrm{L}}$ and $K_{\mathrm{r}}^{\mathrm{PC}}$, relative association constants of lipids $\mathrm{L}$ and $\mathrm{PC}$, respectively; $\Delta G=\Delta G_{0}(\mathrm{~L})-\Delta \mathrm{G}_{0}(\mathrm{PC})$, differential free energy of association.

These relative association constants and the differential free energies of association $\Delta G_{0}(\mathrm{~L})-\Delta G_{\mathrm{o}}(\mathrm{PC})=-R T \ln \left(K_{\mathrm{r}}^{\mathrm{L}} /\right.$ $K_{\mathrm{r}}^{\mathrm{PC}}$ ) deduced from them are also given in Table $\mathrm{I}$.

Exchange Rates. The influence of lipid selectivity on the exchange dynamics at the lipid-protein interface can be analyzed by spectral simulations using the exchange-coupled Bloch equations (Marsh \& Horvâth, 1989). The simulated spectra are shown together with the experimental spectra from the lipid selectivity series for DM-20 by the dashed lines in Figure 2. The line shapes of the fluid and motionally restricted spectral components were matched with the fluid lipid and protein-alone reference spectra, as previously described (Horvâth et al., 1988a). All the two-component spectra could be fitted with various proportions of these two components and the appropriate exchange rates. Each fit was optimized for minimum fitting error; normalized mean square deviations were less than $1 \%$.

The two variables that can be determined from such simulations are the off-rate $\tau_{\mathrm{b}}{ }^{-1}$ and the fraction $f$ of the motionally 


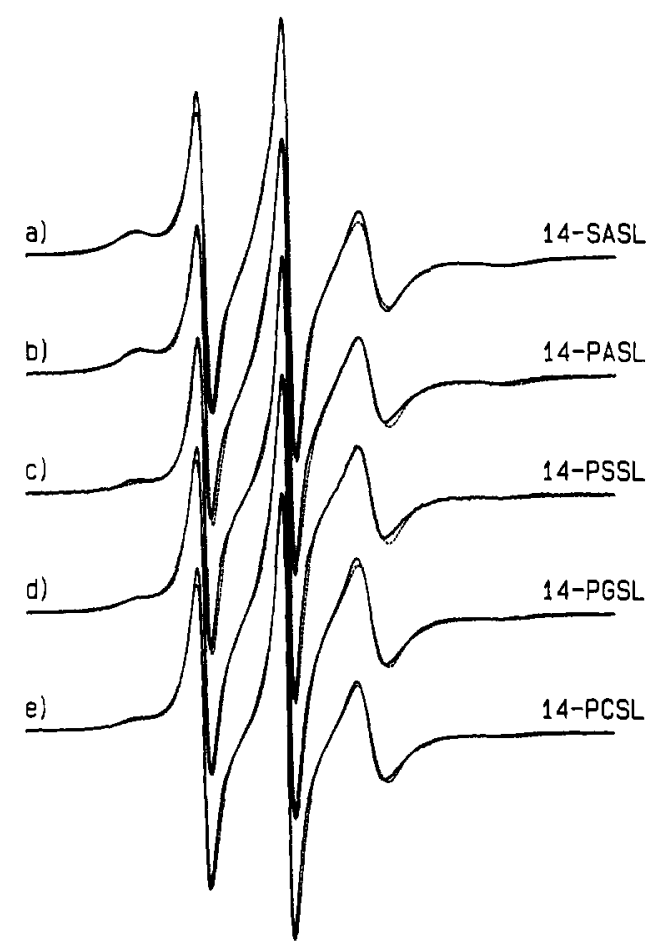

FIGURE 2: ESR spectra of different spin-labeled lipids in DM-20/ DMPC recombinants of lipid/protein ratio $28: 1 \mathrm{~mol} / \mathrm{mol}$ (full lines) and simulations using the two-component exchange model described in the text (dashed lines). rms deviations between experimental and simulated spectra are in the range $0.5-0.9 \%$. (a) Stearic acid spin-label, 14-SASL; (b) phosphatidic acid spin-label, 14-PASL; (c) phosphatidylserine spin-label, 14-PSSL; (d) phosphatidylglycerol spin-label, 14-PGSL; (e) phosphatidylcholine spin-label, 14-PCSL. $T=30^{\circ} \mathrm{C}$; total scan width $=10 \mathrm{mT}$.

restricted component. The ratio of the off-rate to the on-rate $\tau_{\mathrm{f}}^{-1}$ is determined by the condition for material balance:

$$
f \tau_{\mathrm{b}}{ }^{-1}=(1-f) \tau_{\mathrm{f}}{ }^{-1}
$$

Substituting this condition into the equation for equilibrium association (Brotherus et al., 1981) yields

$$
\tau_{\mathrm{b}}^{-1} / \tau_{\mathrm{f}}^{-1}=\left(n_{\mathrm{t}} / N_{1}-1\right) / K_{\mathrm{r}}
$$

where $n_{1}$ is the total lipid to protein ratio and $N_{1}$ is the number of association sites at the protein interface. It can be assumed that the on-rate, $\tau_{f}^{-1}$, is constant for a given lipid/protein ratio because it is diffusion controlled (Horváth et al., 1988b). Hence for different spin-labeled lipids, the off-rate constants, $\tau_{b}{ }^{-1}$, should be inversely proportional to their relative association constants, $K_{\mathrm{r}}$, with the protein. This correlation plot between $1 / K_{\mathrm{r}}$ and $\tau_{\mathrm{b}}{ }^{-1}$ is shown in Figure 3 , and the data are seen to conform to the inverse relation predicted by eq 3 .

\section{DisCUSSION}

The PLP molecule of the central nervous system myelin has been found to be preferentially solvated by negatively charged phospholipids, and the electrostatic origin of this lipid specificity has been studied by $\mathrm{pH}$ and salt titration experiments (Boggs et al., 1977; Brophy et al., 1984; Horvăth et al., 1988b). In these experiments, the PLP was not separated from the DM-20 protein, and hence, the reported lipid specificity pattern was a weighted average of the specificities of these two proteins. The hydropathy profile and distribution of noncompensated charges in the amino acid sequence of PLP are given in Figure 4. The deleted sequence in DM-20, which is indicated by the shaded box in Figure 4, contains five positively and two negatively charged amino acid residues and forms a

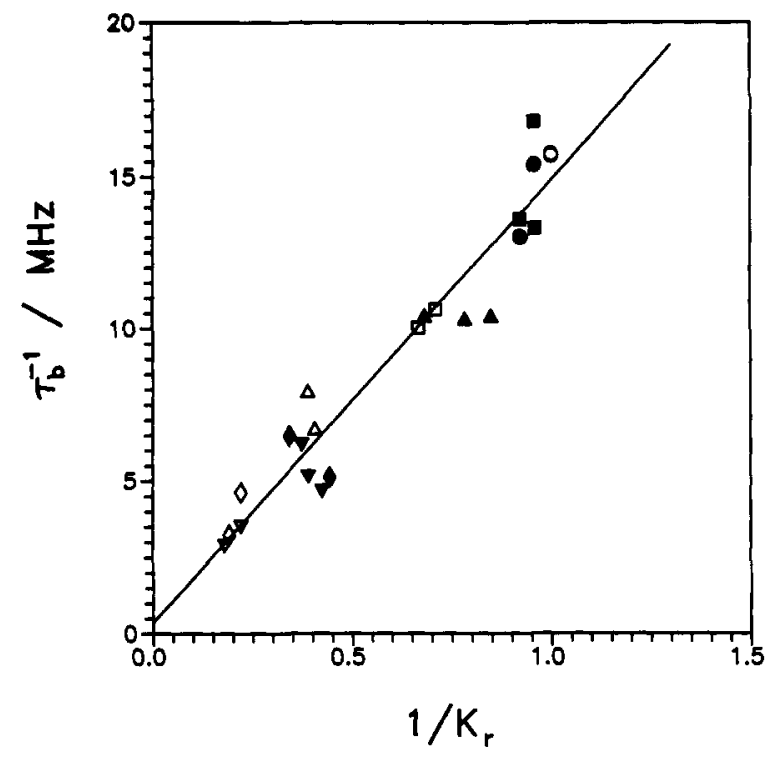

FIGURE 3: Correlation diagram between the off-rate constants, $\tau_{b}^{-1}$, and the relative association constants, $K_{\mathrm{r}}$, for different spin-labeled lipids in DM-20/DMPC (filled symbols) and mixed (DM-20 + PLP)/DMPC (open symbols) recombinants of lipid/protein ratio 28:1 $\mathrm{mol} / \mathrm{mol}$. Phosphatidic acid spin-label, 14-PASL $(\diamond, \diamond)$; stearic acid spin label, 14-SASL $(\nabla, \nabla)$; phosphatidylserine spin-label, 14-PSSL $(\Delta, \Delta)$; phosphatidylglycerol spin-label, 14-PGSL $(\square, \boldsymbol{\square})$; phosphatidylcholine spin-label, 14-PCSL $(0,0)$.

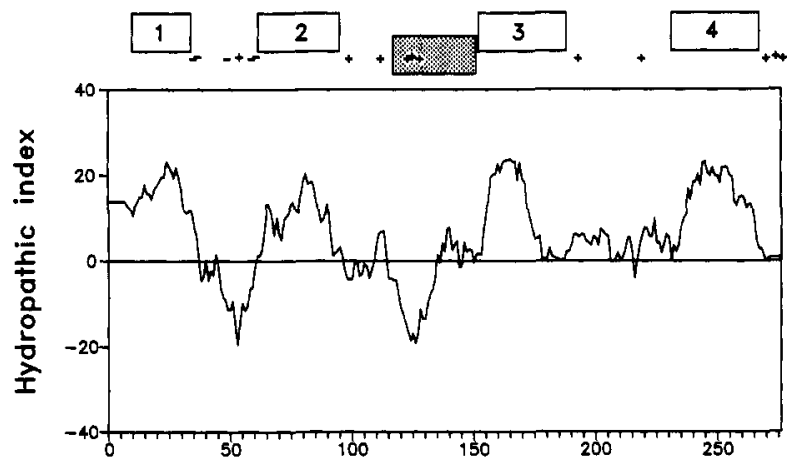

FIGURE 4: Hydropathy plot for the myelin proteolipid apoprotein (PLP) and the myelin protein of $23 \mathrm{kDa}$ (DM-20), calculated with a nine-residue window. The four hydrophobic regions are indicated by numbers, and the shaded box indicates the internal hydrophilic deletion (residues 116-150) in DM-20. The hydrophobic and hydrophilic regions lie above and below the $y=0$ axis, respectively. Charged residues are indicated by plus and minus signs, except that oppositely charged residues not more than four sequence positions apart are considered to neutralize each other.

long hydrophilic loop connecting a transmembrane sequence and a hydrophobic loop (Stoffel et al., 1983, 1984; Laursen et al., 1984; Diehl et al., 1986; Simons et al., 1987). Since the positively charged residues are located at the membrane interface, this deletion might be expected to decrease the relative association constants of acidic lipids, giving a more uniform lipid selectivity pattern for the various phospholipids. The lower selectivities obtained here for DM-20 complexes relative to PLP-containing complexes are consistent with this prediction, indicating that these residues play an important role in establishing the lipid specificity pattern of PLP.

The protein-associated fraction in the mixed (PLP + DM20)/DMPC complexes is a weighted average of the intensity of the motionally restricted components from the two proteins. Assuming that the DM-20 and PLP molecules are solvated independently and there is no direct exchange between the two sets of association sites, the observed fraction of the motionally restricted component can be given in terms of the fractions 
associated with the DM-20 and PLP molecules, $f_{\mathrm{DM}-20}$ and $f_{\mathrm{PLP}}$ :

$$
f_{\text {obs }}=X_{\mathrm{DM}-20} f_{\mathrm{DM}-20}+X_{\mathrm{PLP}} f_{\mathrm{PLP}}
$$

where $X_{\mathrm{DM}-20}=0.29$ and $X_{\mathrm{PLP}}=0.71$ are the mole fractions of DM-20 and PLP, respectively. From the values of Table I, the true relative association constants for 14-PASL, 14SASL, 14-PSSL, and 14-PGSL in PLP/DMPC complexes are then found to be $10.4,6.5,2.2$, and 1.8 , respectively. These are appreciably higher than the previous uncorrected values obtained for the mixture of PLP and DM-20 (Brophy et al., 1984; Table I). The acid lipid association constants for PLP are therefore much higher than those for DM-20 (Table I), corresponding to the reduction in number of net positive charges on the protein by a factor of 2 .

The deletion in DM-20 involves three uncompensated positively charged residues on the extracytosolic side. It is of interest to compare this decrease in protein net charge with the decrease in free energy of association of the acidic lipids. The difference between PLP and DM-20 corresponds to a decrease in free energy of interaction of between 0.5 and 1.2 $\mathrm{kJ} / \mathrm{mol}$ per charge, as deduced from the relative association constants for 14-PGSL and 14-PASL, respectively. For comparison, two unshielded charges with a separation of 10 $\AA$ in a medium of dielectric constant $\epsilon=80$ have a Coulombic interaction energy of $1.7 \mathrm{~kJ} / \mathrm{mol}$. The charges on the protein are most probably shielded to a certain extent, even at the relatively low ionic strengths used in the present experiments.

The effects of the deletion in DM-20 on the lipid specificity should also be reflected in the exchange rate at the lipidprotein interface (Horváth et al., 1988b; Marsh \& Horvâth, 1989). Figure 3 shows that this is in fact the case. The exchange rate of the zwitterionic PC is relatively rapid and has the same value for both proteins: $\tau_{\mathrm{b}}{ }^{-1}=1.5 \times 10^{7} \mathrm{~s}^{-1}$. Virtually no selectivity and fast exchange were observed for PG in the DM-20/DMPC system, but the corrected exchange rate with PLP is reduced to $9 \times 10^{6} \mathrm{~s}^{-1}$. Substantially slower exchange rates were obtained for stearic acid and phosphatidic acid in both cases: $5.5 \times 10^{6} \mathrm{~s}^{-1}$ for DM-20/DMPC and $(2.5-3) \times 10^{6} \mathrm{~s}^{-1}$ for PLP/DMPC (using values corrected as in eq 4), in agreement with the effect of selectivity in retarding negatively charged lipids. PS displayed intermediate off-rates in both lipid/protein systems: $1 \times 10^{7} \mathrm{~s}^{-1}$ for DM-20/DMPC and $6 \times 10^{6} \mathrm{~s}^{-1}$ for PLP/DMPC.

Clearly, the deletion of residues 116-150, including three arginines and two lysines, from the primary sequence of PLP causes a large decrease in the lipid selectivity of this protein. Potentially, such deletions may therefore have considerable influence on the assembly of compact myelin and on other interactions at the membrane surface.

\section{REFERENCES}

Boggs, J. M., Vail, W. J., \& Moscarello, M. A. (1976) Biochim. Biophys. Acta 448, 517-530.

Boggs, J. M., Wood, D. D., Moscarello, M. A., \& Papahadjopoulos, D. (1977) Biochemistry 16, 2325-2329.

Boss, W. F., Kelley, C. J., \& Landsberger, F. R. (1975) Anal. Biochem. 64, 289-292.
Brophy, P. J. (1977) FEBS Lett. 84, 92-95.

Brophy, P. J., Horvâth, L. I., \& Marsh, D. (1984) Biochemistry $23,860-865$.

Brotherus, J. R., Jost, P. C., Griffith, O. H., Keana, J. F. W., \& Hokin, L. E. (1980) Proc. Natl. Acad. Sci. U.S.A. 77, 272-276.

Brotherus, J. R., Griffith, O. H., Brotherus, M. O., Jost, P. C., Silvius, J. R., \& Hokin, L. E. (1981) Biochemistry 20, 5261-5267.

Devaux, P. F., \& Seigneuret, M. (1985) Biochim. Biophys. Acta 822, 63-125.

Diehl, H.-J., Schaich, M., Budzinski, R.-M., \& Stoffel, W. (1986) Proc. Natl. Acad. Sci. U.S.A. 83, 9807-9811.

Eibl, H., \& Lands, W. E. M. (1969) Anal. Biochem. 30, 51-57.

Esmann, M., \& Marsh, D. (1985) Biochemistry 24, 3572-3578.

Gagnon, J., Finch, P. R., Wood, D. D., \& Moscarello, M. A. (1971) Biochemistry 10, 4756-4763.

Horvăth, L. I., Brophy, P. J., \& Marsh, D. (1988a) Biochemistry 27, 46-52.

Horvāth, L. I., Brophy, P. J., \& Marsh, D. (1988b) Biochemistry 27, 5296-5304.

Hubbell, W. L., \& McConnell, H. M. (1971) J. Am. Chem. Soc. 93, 314-326.

Laemmli, U. K. (1970) Nature (London) 227, 680-685.

Laursen, R. A., Samiullah, M., \& Lees, M. B. (1984) Proc. Natl. Acad. Sci. U.S.A. 81, 2912-2916.

Lowry, O. H., Rosebrough, N. J., Farr, L., \& Randall, R. J. (1951) J. Biol. Chem. 193, 265-275.

Marsh, D. (1982) Tech. Life Sci.: Biochem. B4 (B426), 1-44. Marsh, D. (1985) in Progress in Protein-Lipid Interactions (Watts, A., \& De Pont, J. J. H. M., Eds.) Vol. 1, pp 143-172, Elsevier, Amsterdam.

Marsh, D. (1987) J. Bioenerg. Biomembr. 19, 677-689.

Marsh, D., \& Watts, A. (1982) in Lipid-Protein Interactions (Jost, P. C., \& Griffith, O. H., Eds.) Vol. 2, pp 53-126, Wiley-Interscience, New York.

Marsh, D., \& Horvăth, L. I. (1989) in Advanced EPR in Biology and Biochemistry (Hoff, A. J., Ed.) pp 707-752, Elsevier, Amsterdam.

McMillen, D. A., Volwerk, J. J., Ohishi, J., Erion, M., Keana, J. F. W., Jost, P. C., \& Griffith, O. H. (1986) Biochemistry 25, 182-193.

Nave, K.-A., Lai, C., Bloom, F. E., \& Milner, R. J. (1987) Proc. Natl. Acad. Sci. U.S.A. 84, 5665-5669.

Powell, G. L., Knowles, P. F., \& Marsh, D. (1987) Biochemistry 26, 8138-8145.

Simons, R., Alon, N., \& Riordan, J. R. (1987) Biochem. Biophys. Res. Commun. 146, 666-671.

Stoffel, W., Hillen, H., Schröder, W., \& Deutzmann, R. (1983) Hoppe-Seyler's Z. Physiol. Chem. 364, 1455-1466.

Stoffel, W., Hillen, H., \& Giersiefen, H. (1984) Proc. Natl. Acad. Sci. U.S.A. 81, 5012-5016.

Trifilieff, E., Skalidis, G., Hlynck, G., Lepage, P., Sorokine, O., Van Dorsselaer, A., \& Luu, B. (1985) C. R. Acad. Sci. Paris 300, 241-246. 